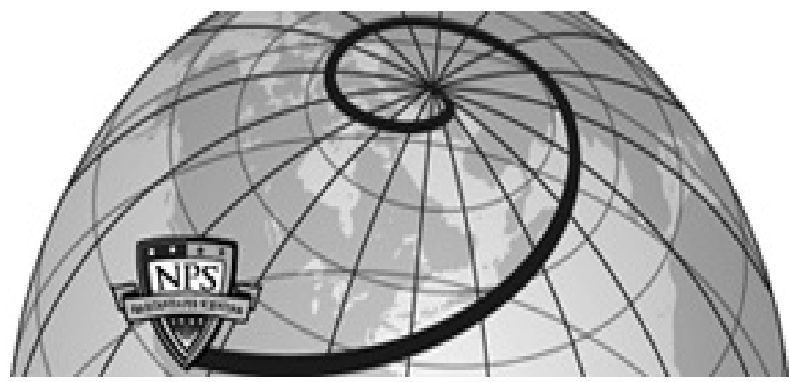

Calhoun: The NPS Institutional Archive DSpace Repository

\title{
Formation and production of sea spray aerosol
}

Spiel, Donald E.; De Leeuw, Gerrit

Elsevier

Journal of Aerosol Science, v. 27, Suppl. 1, 1996, pp. S65-S66.

https://hdl.handle.net/10945/43176

This publication is a work of the U.S. Government as defined in Title 17, United

States Code, Section 101. Copyright protection is not available for this work in the United States.

Downloaded from NPS Archive: Calhoun

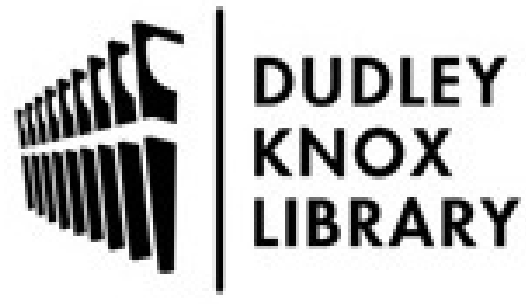

http://www.nps.edu/library
Calhoun is the Naval Postgraduate School's public access digital repository for research materials and institutional publications created by the NPS community. Calhoun is named for Professor of Mathematics Guy K. Calhoun, NPS's first appointed -- and published -- scholarly author.

Dudley Knox Library / Naval Postgraduate School 411 Dyer Road / 1 University Circle Monterey, California USA 93943 


\title{
FORMATION AND PRODUCTION OF SEA SPRAY AEROSOL
}

\author{
DONALD E. SPIEL ${ }^{1}$ AND GERRIT DE LEEUW ${ }^{2}$ \\ ${ }^{1}$ Naval Postgraduate School, Monterey, CA 93943, USA \\ ${ }^{2}$ TNO Physics and Electronics Laboratory, P.O. Box 96864 \\ 2509JG The Hague, The Netherlands
}

\author{
KEYWORDS \\ marine aerosol, sea spray, source function, bubbles
}

The flux of the marine aerosol at the air-sea interface, referred to as the surface source function (SSF), is an important parameter in many processes. Several attempts to derive the SSF have been published, but the estimates vary by orders of magnitude. See Wu [1995] and Andreas et al. [1995] and the references cited therein.

Sea spray aerosol is produced from bubbles bursting at the air-sea interface and, when wind speeds exceed about $7-11 \mathrm{~m} / \mathrm{s}$, by direct tearing from the wave crests (spume drops). There is little information available on these spume drops. Direct measurements in the field are sparse and laboratory experiments have involved only very large spume drops. On the other hand, production of film drops, formed when the bubble cap ruptures, and jet drops, which are created a little later by the collapse of the bubble cavity, have been studied at length in the laboratory. See, for example, Blanchard [1963, 1988] and spiel [1994, 1995, 1996]. Data on the number of droplets produced by bubbles of a given size have been combined with oceanic bubble flux data to formulate the bubble-mediated source function (BMSF). See, for example, Wu [1995] who combined this with the available information on spume droplet production to yield the total source function.

Alternatively, the SSF has been derived by several workers from measurements of the aerosol size distributions at elevated levels (around 10 m) using a model describing the surface layer aerosol concentration gradients based on the balance between production, removal and turbulent transport (e.g., Fairall et al. [1983], Smith et al. [1993]). This approach necessarily yields the effective source function that applies for the level at which the measurements were made, and describes the total effect of film, jet and spume drops. However, comparison of experimental data on the concentration gradients with surface layer profile formulations shows that discrepancies may occur [Davidson et al., 1995] which can amount to an order of magnitude [De Leeuw, 1988]. Also, recent results from numerical simulations of the transport of aerosol over waves by Mestayer et al. [1996] has indicated that the waves can significantly affect the vertical transport. This has not been taken into account in the current models.

Recently, new laboratory based data on both jet and film drop production have become available from spiel. At the same time, field measurements of oceanic bubble size distributions over a wide range of conditions have been obtained by de Leeuw and cohen [1995]. In this paper we propose an approach which combines these data with source functions obtained from simultaneous measurements of aerosol size distributions at several levels. This would yield the total source function from which the spume droplet contribution can be obtained by subtraction of the BMSF. Innovations in this work are: - New estimates of the number of jet drops produced from a single bubble. Using new techniques, Spiel has studied jet drop production in some detail obtaining the number and size of all the drops produced by a bubble of a given size. These results can be used to formulate a more accurate SSF. Present formulations, based mainly on the work of Blanchard and co-workers, provided this information only for the top drop.

- New measurements of the number, size and ejection parameters of film drops during the film opening process.

- The use of oceanic bubble size distributions and empirical formulations of the variation of their concentrations with ambient conditions. Thus far, 
for estimates of BMSF the bubble spectrum has generally been assumed to have a spectral shape that is independent of wind speed, only the amplitude would vary. Work presented in de Leeuw and Cohen [1995] clearly shows the variation of both the spectral shape and the amplitude with wind speed. In coastal seas this is even more complicated and fetch and wave age have to be taken into account.

- The use of simultaneously measured bubble size distributions and aerosol size distributions at several levels in the atmospheric surface layer to derive the BMSF and the total source function, to estimate the contribution of spume drops.

\section{REFERENCES}

Andreas, E.L., J.B. Edson, E.C. Monahan, M.P. Rouault, and S.D. Smith, The spray contribution to net evaporation from the sea: A review of recent progress, Boundary-Layer Meteorol., 72, 3-52, 1995

Blanchard, D.C., The electrification of the atmosphere by particles from bubbles in the sea, Prog. Oceanog., 1, 73-202, 1963

Blanchard, D.C. and L.D. Syzdek, Film drop production as a function of bubble size, J. Geophys. Res., 93, 3649-3654, 1988

Davidson, K.L., P.A. Frederickson and G. de Leeuw, Surface layer turbulence and aerosol profiles during MAPTIP, Propagation assessment in coastal environment. AGARD CP, 567, 25-2 to 25-9, 1995

De Leeuw, G. , Surface layer profiling of aerosol concentrations, particle size distributions and relative humidity, Proc. NATO advanced workshop: Humidity exchange over the sea main experiment (HEXMAX) analysis and interpretation (deBilt/Epe, The Netherlands, April 25-29, 1988) and Techn. Rep. Dept. Atomos. Sci., AK-40, Univ. Washington, Seattle (WA), 80-85, 1988

De Leeuw, G. and L.H. Cohen, Bubble size distributions in coastal seas, Third International Symposium on Air-Sea Gas Transfer, Heidelberg, Germany, July $24-27,1995,1995$

Fairall, C.W., K.L. Davidson and G. Schacher, An analysis of surface production of sea-salt aerosol, Tellus, 35B, 31-39, 1983

Mestayer, P., A.M.J. van Eijk, G. de Leeuw and B. Tranchant, Numerical simulation of the dynamics of sea spray over the waves, J. Geophys. Res., In press, 1996

Smith, M.H., P.M. Park and I.E. Consterdine, Marine aerosol concentrations and estimated fluxes over the sea, Q.J.R. Meteorol. SoC., 119, 809-824, 1993

Spiel, D.E., The sizes of the jet drops produced by air bubbles bursting on sea- and fresh-water surfaces, Tellus, 46B, 325-338, 1994

Spiel, D.E., On the births of jet drops from bubbles bursting on water surfaces, J. Geophys. Res., 100, 4995-5006, 1995

Spiel D.E., A hypothesis concerning the peak in film drop production as a function of bubble sizes. Submitted to J. Geophys. Res., 1996

Wu, J., Complete productions of sea spray at various wind velocitiesincluding film, jet and spume drops, Proc. of the Second International Conference on Air-Sea Interaction and on Meteorology and Oceanography of the Coastal Zone, September 22-27, Lisbon, Portugal, Am. Meteorol. Soc., 230-231. 1995 